\title{
Mathematical Infinity "in prospettiva” and Spaces of Possibilities
}

\section{L'infini mathématique "in prospettiva" et les espaces des possibles}

\author{
Giuseppe Longo ${ }^{1}$ \\ ${ }^{1}$ Centre Cavaillès, République des Savoirs, \\ CNRS et Ecole Normale Supérieure, Paris \\ School of Medicine, Tufts University, Boston
}

http://www.di.ens.fr/users/longo/

\begin{abstract}
The Italian Renaissance painters invented the first symbolic form for the mathematical concept of "actual" infinity : the projective point of the perspective. This was the result of a long debate on infinity, in philosophy, since Aristotle, and in theology, during the Middle Age, and had a major fall out in this early geometrization of space. In particular, this invention set the grounds for the construction of the infinite spaces of all possible physical dynamics. In spite of the diversity of the theories in physics (Classical, Relativistic, Quantum ... theories), an a priori "phase space", as a generalization of the infinite Newtonian space-time, is a core presupposition of each theoretical frame. The problem will be posed of the pertinence of this construction as for historical sciences, biology in particular, where the "space of all possible paths" (the list of all phenotypes and their phylogenetic history) cannot be pre-given.

KEYWORDS. Potential infinity, actual infinity, perspective, phase space, evolution.
\end{abstract}

\section{A Short Introduction to Infinity}

There is no space in ancient Greek geometry. By tracing lines, using the ruler and compass as we would say today, measurements are made, figures are constructed, but without an "infinite container" that would be "behind" them, not even a plane as a mathematical, explicitly defined structure. Symmetries - rotations and translations - produce the proof, in the finite, over figures. And potential infinity (apeiron, unbounded) is constructed by means of extensions and iterations. The segment is extended without a finite boundary into a straight line eis apeiron - towards infinity, or with no limit (Euclid's second axiom). If we give ourselves a collection of prime numbers, we can construct a new number which is larger than any element of that collection (Euclid's theorem on the infinitude of prime numbers); an extension and an endless iteration of the finite, from the gesture which traces the line to the construction of integers. Time is infinite in this sense, never being present in our mind in its whole totality. Infinity is not that beyond where there is nothing, says Aristotle in his Physics, but that beyond where there is always something. It is a potential.

Paolo Zellini [1] explains that the Aristotelian distinction between this mathematical infinity to be constructed step by step, in potentia, and the infinity which is "already" there, the actual infinity, and which encompasses everything, will be revived with intensity during the medieval period's metaphysical debate. God is an infinity that is all-encompassing and beyond which there is nothing. But this concept of actual infinity is not so simple. Aristotelians understand it through negation, following Aristotle. But God cannot have a negative attribute. What St-Thomas will do is to exclude the existence of such actual infinity except as attribute of God and of God alone. And this concept of actual infinity will be reinforced; it will take form positively in the minds of men. To a point where the Bishop of Paris, Etienne Templier, will decree in 1277 that actual infinity constitutes a positive attribute of God and of Creation. God, when He so desires, also introduces actual infinity into the world, for example by bestowing Full and Infinite Grace upon a finite woman, Mary - and the 
stakes were ready for anyone who would disagree. This firm "axiomatic posture" certainly contributed to stabilize the concept of infinity.

Zellini is correct in emphasizing the importance of this debate with respect to the birth of a cosmology of infinity which will reach its plenitude, at first mystical, and then scientific, in the infinite Universe and "gli infiniti mondi" of Nicholas of Cusa (1401-1464) and Giordano Bruno (1548-1600).

\section{Infinity in Painting [2]}

The concept of actual infinity is therefore shaped by a metaphysical debate, which circumscribes infinity into a single "thing", forcing the mind to conceive of it in its totality. How will it be picked up by Mathematics, which will make of it a rigorous object of discourse, or even a component of proof? The passage will occur with the invention of perspective ("prospettiva") in Italian Renaissance painting. [3]

The issue of the representation of the space within which to set narrative figures will become a central concern for painters from the end of the XIIIth century onwards. Giottesque "boxes" (those "doll houses", lacking a wall, exposed to the spectator) are settings, in a "local space", that have for purpose to contain the historia and to make intelligible the theological teaching. Yet, there is no global organization of space in the painting, no projective line or point, proposing a "perspective". The human gestures and sufferings of Giotto's bodily masses construct/force tri-dimensional space as "depth": the green heavy body at the lower center, the movements of the arms, the desperation of the angels ... (Deposizione, Cappella degli Scrovegni, Padova, 1303 - 1306):

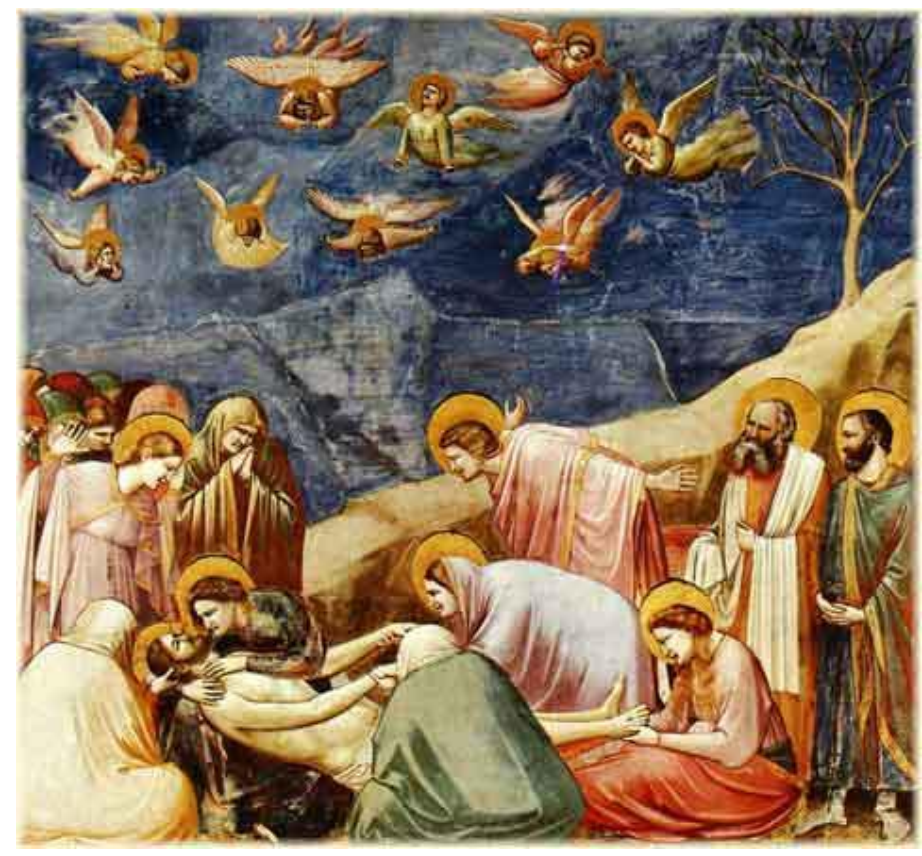

The geometric perspective, closely experimented by Filippo Brunelleschi in 1417, was later defined by Leon Battista Alberti as the result of a construction where man is at the origin of all measurement and where infinity, the convergence point for the orthogonal lines at the base of the painting, is contained, enclosed within the representation (Alberti, De pictura, I, 19, 1435). Since the '80s and in reaction to the inaugural article by Erwin Panofsky (Perspective as Symbolic Form, 1925), art historians, such as Hubert Damisch and Louis Marin in Paris, highlighted the importance of the pictorial revolutions constituted by the invention of costruzione leggittima.

Erwin Panofsky had designated Ambrogio Lorenzetti's Annunciation (below) as being the first geometric construction where vanishing lines converge not towards a single point, but towards a 
single vertical axis ("behind" the column separating Gabriel and Mary). Yet, Daniel Arasse (and Sara Longo, see endnote 2) will go further to extend this intuition to the quite particular surge in complex geometric constructions to be found in annunciation scenes. Their argument is quite relevant with respect to our topic: the particular affinity which existed, during the XVth century, between the Annunciation and perspective, is due to the fact that in Christian history, the main moment where God's actual infinity entered the realm of the finite was that of the miraculous arrival of the son of God born into a human body, Full of infinite Grace. To support his argument, the author bases himself also on a sermon pronounced by Saint Bernardino of Siena, spoken in the Campo in Siena in 1427: the Annunciation is the moment where "immensity comes in measurement $[\ldots]$, the unfigurable in the figure, the uncircumscribable in place, the invisible in vision [...], length in brevity, breadth in narrowness, height in lowness" [4], a number of conceptual paradoxes which are at the origin of spatial paradoxes produced by painters, who brought infinity in the painting, as stressed by Alberti. Daniel Arasse highlights how the most skillful perspectivists play with the rules of geometric perspective in order to show the paradoxical entry of infinity into the finite.

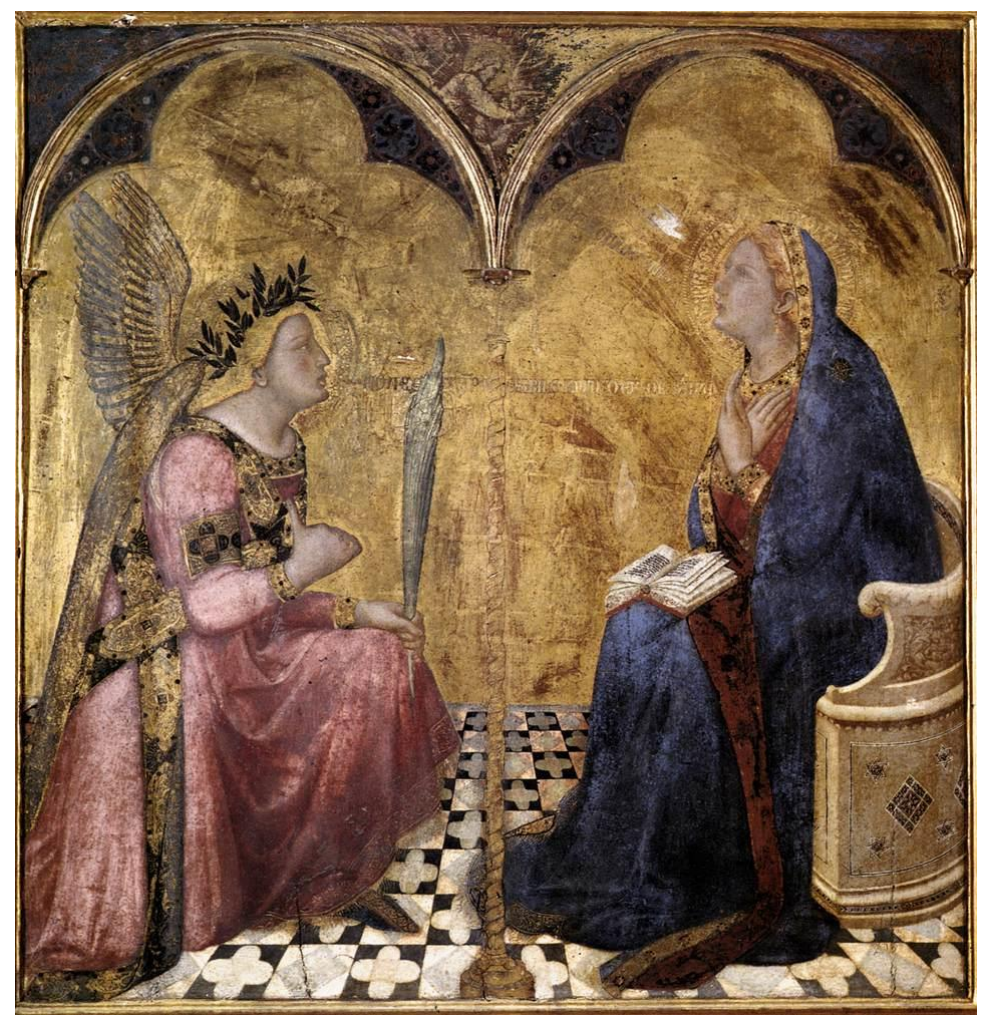

In Lorenzetti's Annunciation (above), a column, often a symbol of Christ, very tangible near the ground, is attenuated towards the top where it overlaps and hides the vanishing axis of perspective, at infinity, an explicit reference to God [5]. In 1344, this was an extraordinary innovation: a rigorously drawn projective space, with a limit line, not just a point, a metaphysical decision. And then, by the effect of the geometry of this floor that goes from man to God, a new space is deployed: God is present in the story being told, albeit hidden, far away at infinity. And the Madonna has a new human dimension: her solid, three-dimensional body accompanies the expression of a nascent humanism. Perspective introduces God as the actual limit, at infinity, therefore as the limit of a space which encompasses everything, including the human spaces which are renewed. And all of the first paintings with "prospettiva" will be annunciations, this unique locus of the meeting between infinitude and finitude. Then, with Piero della Francesca, this painterly exposition of a metaphysical position will also become a technique, without necessarily loosing its religious undertone. In his Annonciations, in particular and with even more evidence than in the other paintings, the projective point will evocate the infinity of God. Piero's book, De prospectiva pingendi, is a real practical treatise of projective geometry, the most important mathematical text of its time as Vasari will state. 
Now, the "prospettiva" enables the painter to organize the space of men and things as well as to select a point of view. The choice of the location of the vanishing point determines the spectator's point of view; it proposes/imposes the way the scene is gazed upon, for example humbly from a low standpoint as in this representation of Saint Sebastian the martyr by Antonello da Messina (1476).

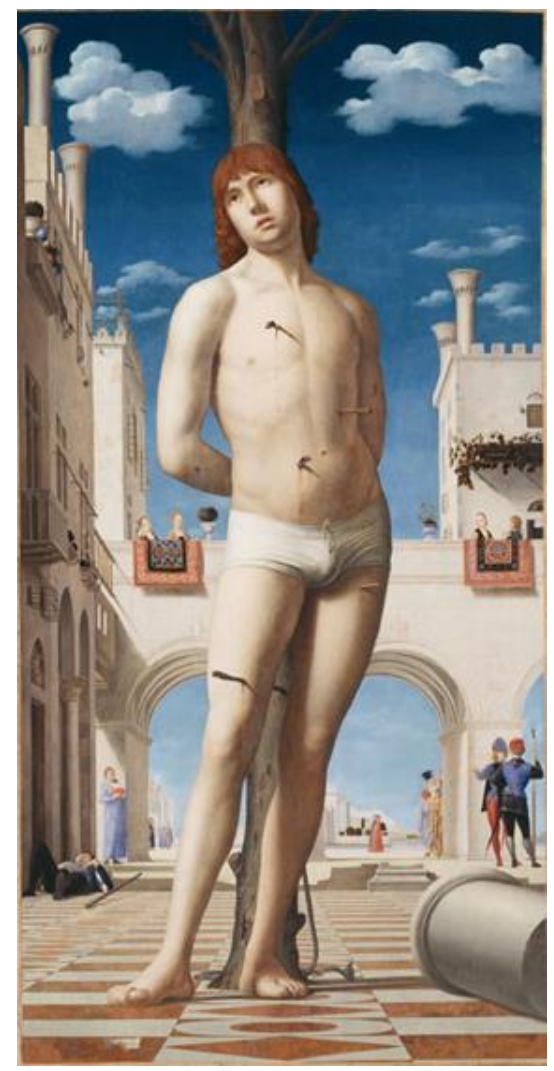

And so this metaphysical and religious cosmology becomes a geometry of space: God, the stars and men will find a new position within it, organized by means of a unifying and modifiable point of view, the choice of the projective point. By the end of the XV century, a variety of constructions are proposed: several projective points are possible, like in Paolo Uccello and Dürer, as well as a spherical perspective. We are quite far from the absolutes beyond the world and beyond space that we had with Byzantine mosaics, for instance in Ravenna. But the true revolution inspired by this pictorial practice and its theorization, is summarized in De Sculptura, by Pomponio Gaurico: the "locus" precedes the bodies. Before painting any object, the painter must construct the spatial frame (the locus) for situating them. Panofsky explicitly refers to Gaurico in order to stress the birth of a Kantian view of space, as the a priori or "condition of possibility" for making science [6].

Painters at one stroke proved how to make actual infinity visible, by its first symbolic representation, and opened the way at the forthcoming mathematics of infinity, including the infinite spaces, from Descartes and Desargues to Newton. Art preceded mathematics or ... weren't many of these painters also excellent geometers? Moreover, this (re-)organization of space, this new talent for choosing a "prospettiva", a technique that will soon become widespread in Europe, will help Copernicus, Kepler and Galileo to "see" the solar system from the "point of view of the Sun", the new "prospettiva" of modern science [7].

Other constructive experiences of space made the invention of the modern mathematical notion of space possible. Cartography, in an age of explorers, surely contributed to it, as well the renewed urbanism that allowed to view and organize the space of the city, as a unity (see Pienza, in Tuscany). However, it would be wrong to oppose these historical experiences and consider one as the privileged origin of the modern geometry of space. A (fundamental) mathematical invariant is always the result of a plurality of acts of experience: its invariance w.r. to different conceptual and practical frames is an essential component of a rigorous mathematical formulation, independent of 
each specific praxis, but rooted in all of them and in the transformations from one construction to another. However, the role of space as a priori of knowledge, so fruitful in the mathematization of physics, from Newton to Relativity Theory and Quantum Mechanics, will be questioned below, in relation to the historicity of the sciences of life.

\section{Intermezzo: the Boundary of Time}

Since Aristotle, time is considered as a paradigmatic form of potential infinity, because it is never present in its totality in our mind. In fact, which "temporal" sense would have its projective limit [8]? However, it is interesting to see that this new arrival, in mathematics, the concept of actual infinity, was constituted through a religious debate, and came to be through painting, the latter being explicitly mathematized as we observed, in particular by the great painter and geometer Piero della Francesca. Note though that the conceptual and geometric construction of an infinite space does not necessary base itself on actual infinity: Descartes' space can very well be conceived of as potential infinity produced, in principle, by an endless extension from its point of origin. Yet, infinite spaces were first conceived in paintings, by "projection", over a plane. Clearly, actual infinity is inherent to projective construction, when it is used for the two-dimensional representation of a threedimensional space. And the projective point objectivates actual infinity: it shows it, there, in the depths of the painting. One may dare to summarize this process as follows. In the Renaissance, space was described in mathematics, by first drawing it in two dimensions. This made visible and, thus, intelligible, at once, actual infinity and three dimensional space, by organizing it by the projective limit - the result of a metaphysical debate.

Two centuries later, Desargues will render this projective synthesis between actual infinity and geometry fully mathematical. By the Differential Calculus, Newton and Leibniz will propose the analytic notions of derivative and of integral as operations at the infinite limit, in the absolute infinity of God's space, as for Newton.

Cantor, in the $19^{\text {th }}$ century, will further objectivate actual infinity, by means of a syntax, by giving it a name and associating a symbol to it. By manipulating it algebraically, up to the invention of an Arithmetic of infinities, that is of ordinals and of transfinite cardinals. Nothing is better for stabilizing a concept than a mathematical praxis, a technical usage of a sign for the concept of which the meaning will be enriched by this very usage. The debate on the infinity of God will also be of interest to Cantor, a deeply religious man: God will be (at) the limit of all limits, beyond, at the limit of all these transfinites.

It must be noted that, in all of these cases, mathematical infinity is a tool for the intelligibility of the world. In Renaissance painting, projective geometry, a mystical decision, organizes at once the space of God and of man, for a fuller humanity. From Descartes to the actual infinity of Newton and Leibniz, mathematical physics will describe finite movements around us by means of infinity - the limit operations of derivative and integral calculus. In logic, from Gentzen (1935) onwards, the ordinal analysis of proof will be based on Cantor's Arithmetics of Infinity [9]. Besides, as Galileo explained to Simplicius, in the analysis of a mathematical sphere based on a plan, "Mathematics is a science at the infinite limit". [10] The finite fetichizes iteration and remains its prisoner [11]. Infinity instead organizes the finite. The finitist formalist who rejects infinity, by declaring it beyond the world and Physics, does not understand the human sense, with respect to our designs and praxis, of this gesture which sets infinity in the world, by structuring it through language, geometry and symbolic writing. The epistemology of this organizing concept must first be "historical": a history of ideas and of the constitutive praxes, a dynamical history, to be always re-thought, in time. 


\section{The Rational Spaces of Commerce and Physics [12]?}

The birth of modern science was achieved by the construction of an infinite space of possibilities, a space and time within which any possible phenomenon or physical dynamic may exist. Choosing the origin of Cartesian coordinates proposes the reference system within which physics after Galileo will be constructed. In fact, Descartes' analytical approach sets the origin and measurement of space; by this, it gives it a "prospettiva", enabling to frame and understand the world.

In the rich and novel Galilean relationship between experiments and theories, physical theorizing is meant to provide intelligibility of phenomena as well as predictability: one first observes and measures, then the theory should produce a prediction capable of confirming it. The scientifically, or mathematically, expected future was set at the core of the understanding of modern science. Unpredictable (random) events are produced only by human activities, like financial ones or games, closely analyzed in original statistical terms by Pacioli (1445 - 1517), Cardano (1501- 1576), Galileo [13]. As for natural phenomena, predictions are made in the space and time of physical events, mathematically described by the Cartesian analytic representation of space enriched by Galileo's relativity: the modern space-time of phenomena is born from an analysis on how to go from one (Cartesian) reference system to another while preserving physical laws, inertial movement in particular. More precisely, in the pre-given infinite space-time of all possible trajectories, the invariants are described as symmetries by Galileo's group.

Once again, however, I would ascribe the turning point towards the myth of a scientific expectation of a possible (and predictable) future to the early Italian Renaissance. The audacity of seeking for a rational insight into the future, within a given space of possibilities, goes back to the appreciation of progress and of possible estimates of it, in Italy, in the XIVth and XVth centuries. This is when artisan technologies, even great productive structures (the "arsenale di Venezia" to which Galileo refers) began to change the relationship to Nature itself. And this is also when the bank credit was invented, at the time of Lorenzetti's painting, also in Tuscany. Mathematics will come to play a massive part in this progress: from Fibonacci da Pisa (1170 - 1250) to Pacioli, mathematicians proposed their calculi to merchants. Pacioli, in particular, with his Summa de Arithmetica, Geometria and other writings, considerably developed the Arithmetics of Fibonacci and invented the "partita doppia", a fundamental tool for finance and commerce.

Lending money was finally allowed around the mid-XIVth century in Italy, under the form of the "letters of credit" or early paper money. No more a sin, one could bet on possible future progress, obtain money from a bank, then invest, expect the return of the money, plus interest, and also obtain personal gain. This novelty was an economic and a conceptual revolution. There was no more need for magic or divination in the expectation of progress and in the capacity to foresee the future, but instead rational, even mathematical knowledge. Of course, hazards were possible, but within a perfectly pre-given space of possibilities: like throwing dice-it is a risk, but within the six possible outputs, no more, no less - and the symmetries of the dice determine the probabilities. Having expectations and betting is rational: within a pre-given space, one can compute the probabilities and evaluate the risk. Human production of random events could also be partially mastered, by statistics and probabilities.

And thus arose the society of an expected future progress, in a predetermined list of possible worlds - the society where one can dare to borrow and lend money as well as to construct scientific knowledge within a mathematically pre-determined albeit infinite space-time; a science, where it is possible to predict an economical or commercial action or, by a scientific theory, the output of an experiment.

Later on, Newton, Leibniz, Laplace and many others will give us the mathematics of modern "state determined systems". Indeed, by solving Newton's equations in the spaces of Descartes "one 
must be able to predict all future events of mechanics" (celestial mechanics, said Laplace, but he was actually thinking of the entire physical world). Pascal's and Laplace's mathematical analysis of probabilities scientifically deal also with unpredictability, but randomness for them is extraneous to mathematical determination and must be analyzed in probabilistic terms. In any case, for them, unpredictable events happen within the infinite but pre-determined Cartesian space of all possible trajectories and facts. This space of observables which will be successively generalized to the phase space (that is, of relevant observables and parameters). Borrowing originally from the invention of immense painters, mathematics and physics went well beyond: a better understanding of physical dynamics requires their embedding in a more general notion of space, not just the Newtonian ones. Position will be enriched by momentum, time by energy in order to obtain the minimal (phase) space for analyzing physical dynamics.

In such spaces, Poincaré will understand unpredictability within determination, by showing us the unpredictability of perfectly deterministic dynamics: non-linear dynamics plus the approximation of measurement produces deterministic unpredictability. Much later, quantum mechanics will integrate randomness into the theory, in the form of intrinsic indetermination [14]. However, the space of possible "trajectories" and events will still be mathematically predetermined, whether they are infinite, from Descartes to Poincaré, or even infinite dimensional-Hilbert and Fock spaces in quantum mechanics. In these spaces, the trajectory of a law of probability, determined by Schrödinger's equation outside of ordinary space-time, will determine the quantum dynamics; the measurement, by projecting onto a real number this dynamic of a density of probability, mathematically describes the indeterministic character of quantum mechanics. Consequently, this theory also gives, a priori, the spaces of all possible evolutions, which may have infinite dimensions, but will accommodate the most unpredictable quantum event, including the creation/annihilation of a quanton.

Note now that the finite description of these possibly infinite spaces, from Descartes to quantum spaces, is made possible by their regularities: they are given in terms of mathematical symmetries (as sets of invariants and invariant preserving transformations). Symmetries thus allow describe these strongly infinite spaces synthetically, in finite words, possibly axiomatically. We are far from Lorenzetti spaces, but these spaces set our doubly asymptotic constructions (infinite spaces of an infinite number of dimensions) on the solid grounds of their early metaphysical origin and subsequent audacious symbolic constructions.

\section{What Possible Spaces for the Evolution of Life Phenomena?}

I think that this is where we are stuck now: in the analysis of the living, both as biological and as societal entities, we understand that there is no way to (mathematically) pre-define the very space of possible evolutions, of the "phases" of life phenomena. Let's try to further clarify this claim [15]. The randomness of dice or coin flipping, of a quantum event, as said earlier, takes place in a pregiven space of possible dynamics. We are able to give ourselves mathematical infinity at once, by geometry, analysis and algebra, since the Renaissance painters, and use it in physics, since Descartes, Desargues, Newton and Schrödinger's Hilbert Spaces. Their symmetries (the mathematical invariants) enable to define geometrically and formally these infinite spaces (of phases, of possibilities).

In contrast to this mathematical predefinability of physical phase spaces, there is no way to predetermine the space of possible future phenotypes (biological forms) along evolution-and phenotypes, or even organisms, constitute the biologically relevant observables [16]. By no means was there a sign of the nose of mammals in the bacterial DNA of 600 million years ago, no more than there was in their forms. And we could not have placed into a list of possibilities the internal bones of their ears, as derived from the double jaw of a few vertebrates from 200 million years ago 
(an example of Gould-type "ex-aptation"). Any phenotype is the result of a vast genetic network as well as evolutionary, changing epigenetic and ecosystemic interactions.

Even next century's list of possible biological events, eukaryotes' forms for example, is not in mathematically pre-given spaces. Along evolution, phenotypes and ecosystems co-constitute themselves and jointly produce the space of possibilities. And the slightest fluctuations in these interactions within, or even between, various levels of organization do not only change "trajectories" within the phase spaces, as in physical dynamics, but change these spaces themselves. The symmetries that beautifully ruled physics are continually changed: as we summarize elsewhere, biology is a never identical iteration of a morphogenetic process [17], which simultaneously shapes the ecosystem. Structural stability preserves some global symmetries (e.g. basic bodily bauplans), but each mitosis is a symmetry change: the two novel cells are never identical, not even to the mother cell. This "never identical" is a change of symmetry. Typically, after a mitosis in a multicellular organism, it is due to a diversity of the proteome, of DNA, of the membranes, of chromatin ..., of the reconstitution of the matrix of a tissue.

And this is fundamental for the variability and diversity that are at the core of evolution and ontogenesis. The permanent changes (in symmetry), in particularly with respect to relevant observables, the phenotypes, are at the basis of variability, hence of diversity, and of the very possibility of the living state of matter. They enable selection among new forms, create adaptability and contribute to the modification of the ecosystem itself.

In short, the phylogenetic and ontogenetic trajectory of an organism is a cascade of symmetry changes [18].

Of course, then, the exclusively molecular analyses, of which the observables are pre-definable, are intrinsically incomplete, albeit very useful: they do not even manage to describe the hereditary transmission of certain acquired deformations in the membrane of ciliates, nor the dynamics of the proteome during modifications induced and inherited from the lactose operon - so in this case, at a purely molecular level. Indeed, the genotype often happens to be a follower more than a driver of phenotypic change [19].

Mathematics is a science of invariants and invariant preserving transformations, hence of symmetries. Will we be able to invent new mathematics to deal with continual symmetry changes? Why not? The founding fathers invented their tools, the mathematics of invariance, from Euclid to Newton and Riemann and Grothendieck (a topos, a categorical notion, is the actual maximum of a philosophy of mathematics as science of invariants and invariant preserving transformations).

In any case, we need to dare, in order to deal with life as well as with economics, far away from the absurd theories of equilibrium: there is no ecosystem nor a society "at equilibrium", unless everybody is dead, not even tending or close to equilibrium. Life is not only a dynamic, a process, far away from equilibrium. It is always in "transition", on a critical threshold: from a mathematical standpoint, it is (in) an "extended critical transition" (see the book with Bailly and the paper with Montévil, both quoted). And the economy is always "in crisis".

\section{Intermezzo: the Possibilities of Finance}

The need for change in our conceptual frameworks comes also from the recurrent crises of the bank lending system, a system which contributed largely in starting the whole story six centuries ago, in Toscany: that is, the notion of progress, rational and scientific prediction, and the mathematics that will ensue, since Pacioli. These audacious and once fruitful bets on a foreseeable future, described in a mastered list of possibilities, have now become the pure transferal of wealth towards the richest, totally disconnected from the work-value. The mathematics of finance provides 
the tools, without any further correlation with any sort of industrial or social productivity. Their objective is not prediction, but an invention of possibilities, that is, of constructing new possibilities for these investments/bets - the derived products, or derivatives. Its aim is not just to estimate probabilities, but more to construct new possibilities for bets, to shape unforeseeable markets and to distribute the risk maximally throughout the world, so that workers in China and India will buy the debts caused by risks taken by American finance.

Financial mathematicians have played a major role in this process. "Derived financial instruments" have been invented as "derivatives" in the mathematical sense (first, second order...): they express tendencies. They were then combined, creating new "correlation surfaces", which compare and relate rates. The latter are also evaluations of the tendencies of a price, of a good, of a derived product. And the predictions which are associated with them have shaped the markets: these analysis surfaces determine the rates to come, because they are expected. Note that by mathematically analyzing the planets, in principle, we do not change their trajectories. In quantum physics, the instrument of measurement indeed serves as an interface with "reality" and creates a new object. But this is a "constitution of physical objectivity", always identical in principle - the experiments can be iterated. On the financial markets, predictive mathematics creates values by proposing predictions: the stock market prices largely depend on the prediction, as anticipation, which is a mathematical result whenever possible, with little or no correlation to any "intrinsic" value whatsoever (work-value, typically - the value of a good as sum of all the work meant to produce it).

To summarize, in the absence of a pre-given phase space and therefore of the possible predefinable economic evolutions, the mathematics of finance was able to play the game of inventing, without limit and outside of any shared meaning and value, possible observables and to mix them in an always new and creative way (for example, by securitization - the endless mix and embedding of securities, obscure to the buyer).

As a mathematician, I feel deeply offended by this immoral use of our beautiful science, bought with money in order to organize theft and the transferal of wealth towards the richest $1 \%$ of the world (during the Bush years, $80 \%$ of the GDP's growth was transferred to the richest $1 \%$ of Americans - an extraordinary political and mathematical feat!). We must react from both an ethical and a scientific standpoint - as, historically, mathematics has been shaped through its use. Yet we do not react [20].

\section{Back to Science}

So apart from mathematically organized financial swindles, rich in auto-predictive symmetries, in what concerns biological evolution, we must face a major challenge: the emergence of new "phase spaces" or, more specifically, of new observables which could require their own mathematical dimension. To give a very simple example, biological rhythms (respiration, heartbeats... invented by animals and very different from clocks and physical rhythms) are better understood by setting them in a second temporal dimension, thus by proposing a new observable. The time of life phenomena then becomes two-dimensional. Maybe we could all encode within one dimension: encoding, encoding... and loss of meaning as with all reductions, when they work.

In three book and in several downloadable papers, with Francis Bailly, Maël Montévil and Ana Soto (see footnotes and http://www.di.ens.fr/users/longo ), we hinted at novel conceptual (and mathematical) structures which aim at a better understanding of the physical singularity of the living state of matter: the change of perspective regarding symmetries is at the core of our scientific proposal. The idea of a pre-given space of possibilities in which, since Lorenzetti, it is even possible to set God, no longer suffices. Predictability, not even of the space of possibilities, is no longer at the center of knowledge construction, in biology. This construction aims at the understanding of the 
historical contingency of life (and, eventually, society—but we will not develop our analysis that far). This must not hinder our awareness of the role of our activity in a totally unpredictable world, where we judge for the better, by making explicit the perspective (and values) that guide our actions.

In short, the theoretical challenge is to invent tools for understanding, but not necessarily for prediction, as René Thom was already saying. Darwin's Theory of Evolution predicts nothing - yet it provides an extraordinary framework for knowledge. So, qualitative estimates regarding the effects of an activity may allow us to act in the world, if these estimates are grounded on criteria of robustness of development, as (increasing) diversity and adaptability. These words, in a societal context, mean justice (which alone makes a society "robust", by diversity in particular) and democracy (adaptation through change).

Science is one of our active forms of being in the world, between knowledge and praxis. We construct knowledge also to act within this world and we indeed need predictability, but it is possible that it is provisional and qualitative, that we will be required to free ourselves from the myth of these pre-given possibilities, a myth as beautiful and soothing as Piero spaces.

The only assurance we could have regarding wether an action works for the best (or according to expectancies) resides in taking an ethical stance: to be critical regarding the very principles of knowledge we employ, in science; always maximizing democracy and justice, both locally and, as much as possible, in perspective, in societies able to change course by means of democratic control.

\section{The Transferal of Mathematical Tools}

The power and elegance of these mathematical frameworks for the intelligibility of the world, the infinite pre-given spaces, from the projective spaces of painting to the most complex phase spaces of theoretical physics, as well as their symmetries, are not adapted to phylogenetic and ontogenetic dynamics. It is therefore necessary to gain some perspective before transferring tools from the physico-mathematical to biology (and to the social sciences) and to reflect about these tools. One can get the impression that too many colleagues prefer their equations and techniques to the biological (and social) phenomena they claim to study. This was not the attitude of the revolutionary thinkers who made science by inventing their own mathematics.

In this radical lack of rational predictability, historical knowledge in biology, such as Darwinian evolution, provides the tools for understanding and, thus, acting on nature. As for societal knowledge, where decisions must be made, if an action aiming for justice produces the opposite effect (this can happen), democracy, we say, is there to ensure the adjustments, to impose a correction: it is adaptive. But this requires critical thinking, which must be at the heart of science and constitute its relationship to philosophy. This is why one of the projects of neo-liberalism is to obliterate or dilute the latter and to subordinate the former to the "market of knowledge". Knowledge in this market must absolutely not be critical, but subordinated to expectancies and to evaluations exclusively in terms of possible applications: "there is no more difference, today, between theory and application", we are told - with the objective of breaking any theory, especially if it is critical and original, beyond of any foreseeable application. Such knowledge would be evaluated the way agencies evaluate markets: in compliance with dominant theories - and in science, by means of bibliometric indices.

To summarize and to conclude, biological and human evolution clearly produces lots of nonlinear effects, upon which several mathematicians are working (and among which a rare few consider them far from equilibrium, dissipative systems, or even in critical transitions). But there is much more than that, since evolution creates new observables, in particular by permanent changes of symmetries, in fact of phase spaces. Yet, even with a minimal understanding of evolution and history, the latter being an extension of evolution through language and its writing (unexpected 
when looking at the first tetrapods), we can hope to better our actions, if we do it in a critical and adaptive manner. Moreover, mathematics and thought are not "already there", before our historical praxes; they are rather co-constituted with our changing activities in this very world. We invented the infinite spaces of mathematics and physics by an ontological commitment to the infinity of God, we need to depart now from this powerful metaphysics and invent new conceptual dynamics of the very phase spaces. In our "group", in a broad sense, some is happening in this direction (see the ongoing work by Sarti and collaborators: http://cams.ehess.fr/alessandro-sarti/ ).

[1] P. Zellini, A brief history of infinity. New York: Penguin, 2005 (in Italian: Adelphi, Roma, 1980).

[2] This section is mostly the work of my daughter Sara Longo, whom I thank for everything she has taught me on the subject as well as for her contribution to this article. Please refer to her Doctoral Thesis in Art History "Voir et savoirs dans la théorie de l'art de Daniel Arasse" (2014) and to her works, in particular "L'annonciation en Italie. Enjeux méthodologiques et historiographiques, autour du colloque florentin de 1986. La perspective de l'Annonciation', présentation d'une étude de Daniel Arasse" and "L'intervalle sacré", both in Studiolo, revue de l'Académie de France à Rome (n. 10, 2013, p. 24-32 et p. 75-93), for a much deeper reflection on these topics (see also: https://char.hypotheses.org/membres/sara-longo )

[3] In Italy, there was at the time a heated debate regarding which name to attribute to this new technique: "perspettiva", "seeing through", which will pass into other languages or, more relevantly, a choice of viewpoint, a "prospettiva", as we will see.

[4] Saint Bernardino da Siena, De triplici Christi nativitate, in Opera omnia, Venice, 1745, IV, p.3, quoted in San Bernardino de Siena, Pagine scelte, Milan, 1950, p.54.

[5] Thus, by the mathematically very audacious convergence of the points towards a line at infinity, not just a point, the painter is also giving a symbolic representation of the relation between the infinity of God and His Son: the asymptotic line vs. the column (Christ, column of the Church).

[6] A broad synthesis of the debate on the birth of the modern concept of space and the role of the perspective may be found in V. De Risi "Arte e scienza della sfera. La nascita del concetto moderno di spazio fra la teoria rinascimentale della prospettiva e la geometria di Leibniz"' Sphaera : Forma immagine e metafora, tra Medioevo ed Età Moderna, Olschki, Roma, 2012.

[7] This is a remark in B. C. van Frassen, An introduction to the Philosophy of Space and Time, Random House, New York, 1970.

[8] In the attempt to make Relativity compatible with the Big Bang theory, some physicists think of the origin of time as an asymptotic inverse limit, in inversion with the temporal order given by the expansion of the Universe. In fact, Noether's theorems in particular (the conservation of energy as invariant of the equations of movement by temporal translations) are at the core of the relativistic turn and are incompatible with an origin of time, see F. Bailly, G. Longo, Mathematics and Natural Sciences: the Physical Singularity of Life, Imperial College Press, London, 2011 (translation and revision of the book for Hermann, Paris, 2006).

[9] Infinity becomes part of proof, in fact, as infinity between algebra and geometry, that of the "well-order" of integers, G. Longo "Reflections on Concrete Incompleteness", Philosophia Mathematica 19(3): 255-280, 2011 (Longo's papers are downloadable from https://www.di.ens.fr/users/longo/download.html ).

[10] A story which serves as starting point for a great little book, A. Gargani, Il sapere senza fondamenti, Einaudi, 1975.

[11] G. Châtelet, Les enjeux du mobile, Seuil, Paris, 1993.

[12] A preliminary version of this section appeared in blog interview form in National Public Radios (NPR, USA), http://www.npr.org/blogs/13.7/2011/06/13/137154418/are-financial-and-scientific-views-of-the-worldsimilar\#more

[13] C. Calude, G. Longo. Classical, "Quantum and Biological Randomness as Relative Unpredictability'. Special issue of Natural Computing, vol. 15, 2, 263-278, Springer, 2016.

[14] Calude C., Longo G. Classical, "Quantum and Biological Randomness as Relative Unpredictability". In a special issue of Natural Computing, Volume 15, Issue 2, pp 263-278, Springer, 2016. 
[15] See Kauffman S.A., Investigations, Oxford University Press, USA, 2002 and Bailly, F and Longo, G. Mathematics and the natural sciences: the physical singularity of life. London: Imperial College Press, (original French version, Hermann, 2006), 2011.

[16] Longo, G. "How Future Depends on Past Histories and Rare Events in Systems of Life", in Foundations of Science, (DOI), vol. 23, September 2017.

[17] Soto A., Longo G. (guest eds.) From the century of the genome to the century of the organism: New theoretical approaches, a Special issue of Progress in Biophysics and Mol. Biology, Vol. 122, 1, Elsevier, 2016.

[18] Longo G., Montévil M. . "From Physics to Biology by Extending Criticality and Symmetry Breakings". In a special issue of Progress in Biophysics and Molecular Biology: 106(2):340 - 347, 2011 and Longo, G, Montévil, M \& Kauffman, S. "No entailing laws, but enablement in the evolution of the biosphere". In the ACM proceedings of Genetic and evolutionary Computation Conference, GECCO'12, Philadelphia (PA, USA), July 7-11, 2012.

[19] West-Eberhard M-J. Developmental Plasticity and evolution. Oxford University Press, New York, 2003.

[20] A few do react. We are also trying by starting the Association Cardano for the scientific responsibility, against "scientism" : http://cardano.visions-des-sciences.eu/fr 